\title{
Линейная зона каолиновой коры выветривания г. Вудъявчорр (Хибины): первые результаты
}

\author{
Карпов С.М. ${ }^{*}$, Лялина Л.М., Жиров Д.В., Семёнов В.Л., Тележкин А.А. \\ Геологический институт КНЦ РАН, Anamumbl, zhirov@geoksc.apatity.ru
}

Аннотация. В статье приводятся предварительные результаты исследований каолинитовой коры выветривания линейного типа, обнаруженной в августе 2018 г. на южном склоне г. Вудъявчорр (Хибины). Зона выветривания весьма необычна с позиций минералогии, геохимии и металлогении. Здесь предварительно диагностированы редкие минералы: манганозит $(\mathrm{MnO})$, тантит $\left(\mathrm{Ta}_{2} \mathrm{O}_{5}\right)$, клеберит $\left(\mathrm{Fe}^{3+} \mathrm{Ti}_{6} \mathrm{O}_{11}(\mathrm{OH})_{5}\right)$ и гояцит $\left(\mathrm{SrAl}_{3}\left(\mathrm{PO}_{4}\right)\left(\mathrm{PO}_{3} \mathrm{OH}\right)(\mathrm{OH})_{6}\right)$. В рамках подготовки выборки циркона к изотопно-геохимическому датированию были проведены исследования морфологии и внутреннего строения с выделением основных типов. Внутреннее строение позволяет предполагать, по меньшей мере, три стадии кристаллизации циркона.

Ключевые слова: кора выветривания, линейный тип, гипергенный, каолинит, циркон.

\section{Linear zone of the kaolinite weathering rind at Mt. Vudyavchorr (Khibiny): first results}

\author{
Karpov S.M. ${ }^{1 *}$, Lyalina L.M., Zhirov D.V., Semenov V.L., Telezhkin A.A. \\ Geological institute KSC RAS, Apatity, zhirov@geoksc.apatity.ru
}

Abstract. The article provides preliminary research data on the linear-type kaolinite weathering rind that was discovered at the southern slope of Mt. Vudyavchorr (Khibiny) in August, 2018. The weathering rind appeared to have unusual mineralogical, geochemical and metallogenic properties. Rare minerals manganosite $(\mathrm{MnO})$, tantite $\left(\mathrm{Ta}_{2} \mathrm{O}_{5}\right)$, kleberite $\left(\mathrm{Fe}^{3+} \mathrm{Ti}_{6} \mathrm{O}_{11}(\mathrm{OH})_{5}\right)$ and goyazite $\left(\mathrm{SrAl}_{3}\left(\mathrm{PO}_{4}\right)\left(\mathrm{PO}_{3} \mathrm{OH}\right)(\mathrm{OH})_{6}\right)$ were preliminarily detected here. Their morphology and structure were studied; major types were identified, when zircon samples were prepared for isotopegeochemical dating. The structural pattern suggests at least three stages of the zircon crystallization. Prime studies are planned. Their results are expected to provide a notion on the time and genesis of this geological formation.

Key words: weathering rind, linear type, hypergene, kaolinite, zircon.

\section{Введение}

В июле 2018 г. в ходе поисковых маршрутов на декоративно-поделочный камень в Хибинском массиве (исп.: Семёнов В.Л., Карпов С.М. и Ушко А.В.) на южном склоне г. Вудъявчорр (ущелье Скалистое) была обнаружена мощная зона каолинитов с необычной минерализацией. Линейная зона интенсивно ожелезненных кавернозных пород контрастно выделяется на фоне вмещающих трахитоидных хибинитов. Наиболее интересной является сама зона интенсивной каолинитизации до 15-20 м мощностью и протяженностью не менее 1 км. Объект такого масштаба, как для Хибин, так и для всего Кольского региона обнаружен впервые. Небольшие останцы мезозойской каолинитовой коры выветривания площадного (мощностью до 10 метров) и линейного типов ранее отмечались на метаморфических породах комплекса Имандра-Варзуга и в северных предгорьях Ловозерских тундр, а также по фенитам к югу от Хибинского и Ковдорского массивов (Афанасьев,1980 а, б). Линейные коры выветривания с интенсивным развитием шпреуштейнизации нефелина и гидрослюд вдоль радиальных и центриклинальных разломов Хибин многократно изучались

\footnotetext{
${ }^{1}$ Данная работа и объект исследований стали последними для Сергея Михайловича Карпова. Он один из немногих сотрудников ГИ КНЦ РАН является первооткрывателем реальных месторождений. И этот необычный геологический объект был открыт в июле-августе 2018 г. при его непосредственном участии. Он с душой и интересом начал исследования минералогии зоны каолинитов. Мы взяли на себя труд и обязанность обработать его первые результаты и продолжить исследования этого объекта.

${ }^{1}$ This work and the object of study were the last for Sergei Mikhailovich Karpov. He is one of the few employees of GI KSC RAS who discovered new deposits. And this unusual geological object was opened in July-August 2018 with his direct participation. With great interest he began to study the mineralogy of the zone of kaolinite. We have taken the task and responsibility to process its first results and continue the study of this object.
} 
(Дофман, 1958, 1962, Минералогия..., 1978, Козырева, 1983 и др.), но каолинит в них диагностировался лишь как второстепенный минерал. Окварцевание описывалось в тектонических зонах в районе ручья Свинцовый и г. Юкспорр и объяснялось влиянием близрасположенных ксенолитов ороговикованных пород (Дорфман, 1962). Образование площадных и линейных каолинитовых кор выветривания связывалось с развитием пенепленизации в условиях влажного тропического климата, начиная с нижнего мезозоя (верхнего триаса) и, возможно, до палеогена (Афанасьев, 1980 а, б). Происхождение гидрослюдистых линейных кор, в т.ч. зон шпреуштейнизации в Хибинах, объяснялось миоцен-плиоценовым выравниванием в условиях умеренного климата (Афанасьев, 1980 а, б; Дорфман, 1962, Дудкин, 2002). Рассматриваемая зона является первой находкой мезозойской каолинитовой коры выветривания линейного типа в девонских щелочно-ультраосновных с карбонатитами комплексах.

\section{Предварительные результаты исследований}

Установленная линейная кора выветривания простирается по аз. $65-75^{\circ}$ с С3 падением под углами $50-70^{\circ}$ (рис. 1). В ней отмечается зональность вкрест и, вероятно, по простиранию. Ближе к лежачему контакту выделяется зона брекчирования, окварцевания и кавернозных пород мощностью до 3-4 м (см. № 8 на рис. 1). Здесь гипергенезу предшествовала тектоническая переработка исходных пород, а дальнейшее их изменение сопровождалось интенсивным выщелачиванием и окварцеванием. На участке окварцевания и по направлению к висячему контакту порода полностью преобразована без сохранения реликтов первичных минералов. По направлению к висячему контак-

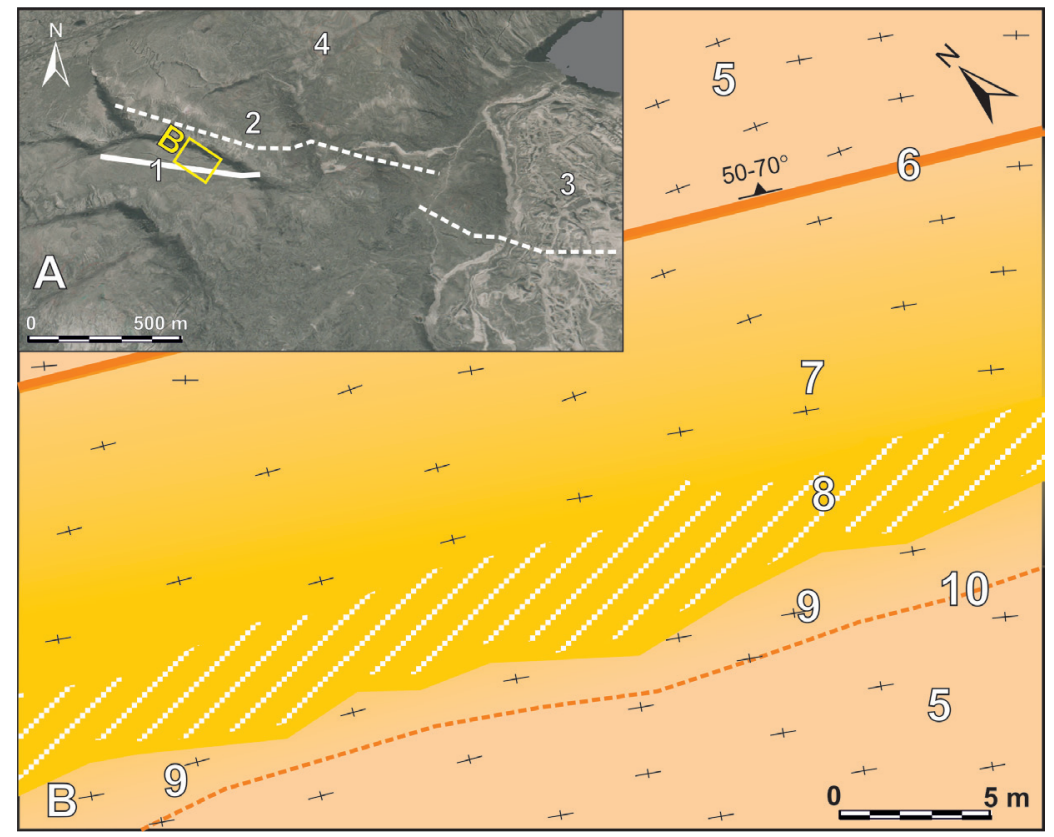

Рис. 1. Схематичный геологический план линейной каолинитовой коры выветривания г. Вудъявчорр.

А) Фрагмент аэрофотоснимка с положением зоны: 1 - прослеженные границы, 2 - предполагаемые границы, 3 - застройка г. Кировск, 4 - южный склон г. Вудъявчорр. В) Геологический план: 5 - крупнозернистые трахитоидные хибиниты (нефелиновые сиениты), 6 - тектонизированный контакт висячего крыла вмещающих хибинитов, 7 - зона интенсивной каолинитизации, 8 - зона интенсивного выщелачивания и окварцевания, 9 - зона слабого развития каолинитизации, 10 - предполагаемая граница развития каолинитизации (лежачее крыло вмещающих хибинитов).

Fig. 1. Schematic geological sketch of the linear kaolinite weathering rind at the southern slope of Mt. Vudyavchorr. A) Fragment of aerial photograph with the zone location: 1 - traced boundaries, 2 - suggested boundaries, 3 - constructions of Kirovsk, 4 - southern slope of Mt. Vudyavchorr; B) Geological plan of the kaolinite zone structure: 5 - coarse-grained trachytoidal khibinites (nepheline syenites), 6 - tectonized contact of the hanging wall of host khibinites, 7 - zone of intensive kaolinitization, 8 - zone of intensive leaching and silicification, 9 - zone of weak kaolinitization, 10 - suggested boundary of kaolinitization (footwall of host khibinites). 
ту каолинит развивается, не нарушая первичную текстуру пород. Доля минералов подгруппы каолинита, включая хорошо раскристаллизованные диккит и накрит, на рассматриваемых участках в среднем составляет порядка 60 \%. По направлению к лежачему контакту интенсивность каолинитизации быстро падает с плавным переходом в неизменённые хибиниты. Обращает на себя внимание незначительная степень тектонической переработки линейной структуры. За исключением относительно узкой зоны катаклаза и брекчирования (примерно 1/3 часть общей мощности) каолинитизация прошла с сохранением первичных текстур. Зона каолинитов прослежена примерно на 1 км на склоне г. Вудъявчорр. Вероятно её фланг выходит в створе простирания в рисчорритах ущелья Городская щель на склоне горы Айкуайвенчорр ( 3.5 км к В-СВ). По результатам структурных исследований (Жиров и др., 2016) предполагается смещение блока с каолинитовой зоной на 50-80 м по сбросу, а блока склона г. Айкуайвенчорр по правостороннему сдвигу на 100-150 м (см. линии 1 и 2 на рис. $1 \mathrm{~A})$.

Проведенные исследования указывают на разнообразие видового состава минералов коры выветривания и специфичность её геохимии. Согласно полученным данным в породах присутствуют минералы различных классов (табл. 1), этом некоторые предварительно диагностированные минеральные виды являются редкими (клеберит, манганозит) и впервые установлены в породах Кольского полуострова.

Для ряда минералов (кварц, рутил, циркон) предполагается полигенеративная природа. Для описываемой зоны установлена геохимическая/металлогеническая специализация с повышенными содержаниями Ti, $\mathrm{Zr}, \mathrm{Nb}, \mathrm{Y}, \mathrm{Ce}, \mathrm{Mn}$ относительно исходных пород.

Для впервые установленной в щелочном массиве Хибины линейной каолинитовой коры выветривания актуальны вопросы её образования и возраста. Предваряющие изотопное датирование минералогические исследования циркона из каолинитовых пород позволили выделить морфологические типы и охарактеризовать особенности его внутреннего строения.

Таблица 1. Минеральный состав линейной каолинитовой коры выветривания.

Table 1. Minerals of the kaolinite weathering linear zone.

\begin{tabular}{|l|l|}
\hline \multicolumn{1}{|c|}{ Класс } & \multicolumn{1}{c|}{ Минеральные виды } \\
\hline Силикаты и алюмосиликаты & $\begin{array}{l}\text { Каолинит, диккит, накрит, монтмориллонит, нонтронит, гр. цеолитов, } \\
\text { циркон, стильпномелан }\end{array}$ \\
\hline $\begin{array}{l}\text { Оксиды, гидроксиды } \\
\text { и оксигидриды }\end{array}$ & $\begin{array}{l}\text { Кварц, гематит, ильменит, анатаз, рутил, манганозит, тантит, гётит, } \\
\text { клеберит }\end{array}$ \\
\hline Галогениды & Флюорит \\
\hline Фосфаты & Гояцит, гр. апатита \\
\hline Карбонаты & Бастнезит-(Се) \\
\hline Недиагностированные & Оксиды и гидроксиды марганца, Ce-Mn-Pb-фаза, Ce-Mn-Sr-фаза \\
\hline
\end{tabular}

Примечание. Жирным шрифтом выделены наиболее распространенные минеральные виды.

Тип 1 представлен гипидиоморфными и идиоморфными короткопризматическими и призматическими кристаллами размером до 0.16 мм по удлинению, Ку 2. Циркон прозрачный, бесцветный или слегка желтоватый, коричневатый. Блеск стеклянный, редко - до алмазного. По внутреннему строению кристаллы различаются. Наиболее распространенными являются кристаллы с внутрифазовой неоднородностью двух порядков (тип 1-1) и одного порядка (тип 1-2). В кристаллах типа 1-1 четко выражены внутренняя (I - «ядро»), промежуточная (II - «мантия») и внешняя (III - «кайма») зоны, которые могут быть отнесены к неоднородности первого порядка (рис. 2 а-в). Во внутренней зоне установлена только фазовая неоднородность, представленная включениями гр. апатита и, предположительно, КПШ (рис. 2 a). Извилистая граница между внутренней и промежуточной зонами указывает на растворение циркона, предшествовавшее росту II зоны («мантии»). Нарастание промежуточной зоны может иметь ярко выраженный асимметричный характер (рис. 2 в). В про- 

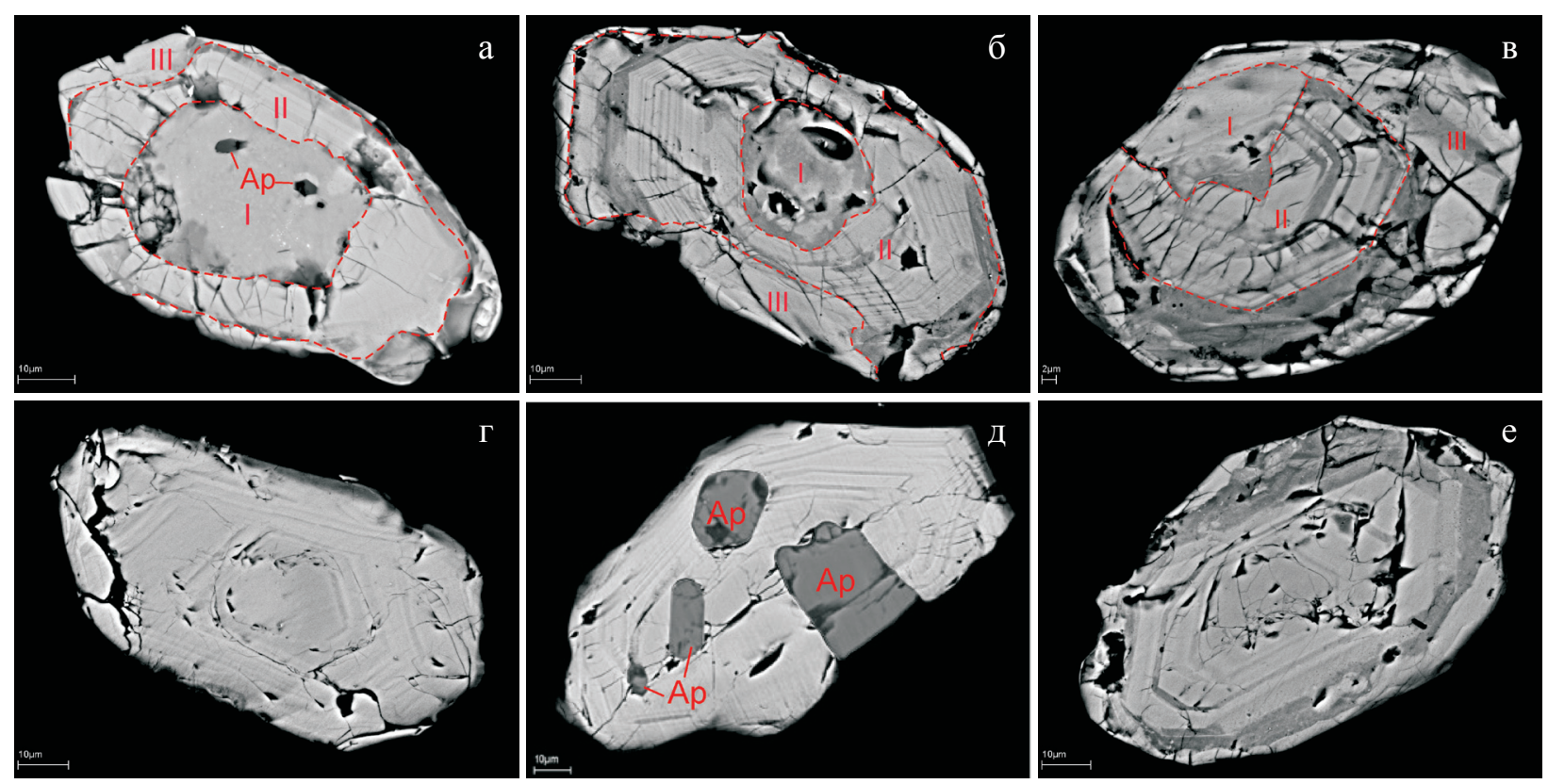

Рис. 2. Внутреннее строение кристаллов циркона 1 морфологического типа.

PЭM, BSE-изображения: а-в) кристаллы с внутрифазовой неоднородностью двух порядков: I - внутренняя, II - промежуточная и III - внешняя зоны первого порядка; г-е) кристаллы с внутрифазовой неоднородностью одного порядка. Ар - гр. апатита.

Fig. 2. Internal textures of 1 morphological type of zircon.

SEM, BSE images. I - core, II - mantle, III - rim zones in zircon crystals. Ap - inclusions of apatite group minerals.

межуточной зоне выявляется тонкоритмичная зональность (внутрифазовая неоднородность второго порядка) с идиоморфными границами зон (рис. 2) и изменением циркона вдоль отдельных зон. Включения не установлены. Циркон промежуточной зоны обычно разбит оперяющими трещинами, отходящими от границы с «ядром» (рис. 2 а,в). Появление подобной трещиноватости объясняют процессами метамиктизации циркона и увеличением объема вещества внутренней и соответствующего растрескивания окружающей зоны (Zircon. Reviews.., 2003). Внешняя зона («кайма») развита не повсеместно, имеет сильно варьирующую мощность и неровную, местами заливообразную границу с промежуточной зоной. На отдельных участках внешняя зона «срезает» рисунок ритмичной зональности второго порядка промежуточной зоны, что в совокупности с заливообразным характером границы указывает на растворение циркона перед ростом внешней зоны. Внешняя зона разбита грубыми разноориентированными (часть из них - оперяющие) трещинами. Трещины и дефекты также подчеркивают границу промежуточной и внешней зон. В кристаллах типа 1-2 про-
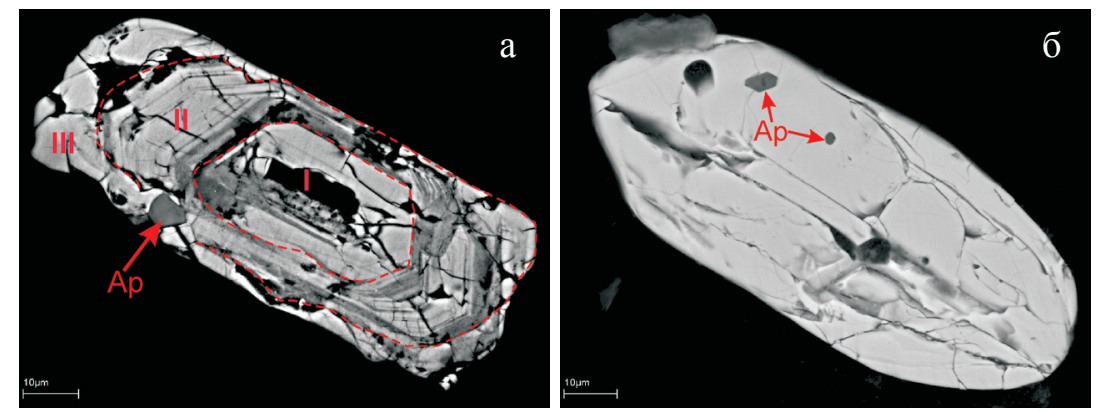

Рис. 3. Внутреннее строение кристаллов циркона 2 морфологического типа.

PЭМ, BSE-изображения: а) кристалл с внутрифазовой неоднородностью двух порядков: I - внутренняя, II - промежуточная и III - внешняя зоны первого порядка; б) однородный кристалл. Ар - гр. апатита.

Fig. 3. Internal textures of 2 morphological type of zircon.

SEM, BSE images. I - core, II - mantle, III - rim zones in zircon crystals. Ap - inclusions of apatite group minerals. 
явлена ритмично-зональная внутрифазовая неоднородность второго порядка (рис. 2 г-е). Границы зон прямолинейные, идиоморфные, мощность зон варьирует. Фазовая неоднородность представлена включениями гр. апатита (рис. 2 д), гр. слюд. В части кристаллов проявлены интенсивные изменения циркона вдоль отдельных зон (рис. 2е). Наименее распространенными в 1-ом морфологическом типе являются кристаллы без явно выраженной или со слабо выраженной внутрифазовой неоднородностью (тип 1-3).

Тип 2 является существенно более редким и представлен призматическими до длиннопризматических кристаллами размером до 0.22 мм по удлинению, Ку $\approx 2.5-3$. Циркон прозрачный, бесцветный или коричневатый, блеск стеклянный до жирного. По внутреннему строению различаются кристаллы с внутрифазовой неоднородностью двух порядков (аналогичные типу 1-1, рис. 3 а) и кристаллы без выраженной внутрифазовой неоднородности («однородные», аналогичные типу 1-3, рис. 3 б).

Тип 3. Помимо ограненных индивидов в породе достаточно широко развит циркон в виде ксеноморфных выделений (агрегатов) в кварце (рис. 4). На отдельных участках угловатые обломки циркона цементируются кварцем (рис. 4 в). Таким образом, в каолинитовой коре выветривания по хибинитам установлены кристаллы циркона только призматического габитуса, характерного для циркона из кислых пород. Внутреннее строение позволяет предполагать, по меньшей мере, три стадии кристаллизации минерала. Ксеноморфные выделения циркона в кварце являются, вероятно, наиболее поздними. Угловатые формы циркона, сцементированного кварцем, могут свидетельствовать о проявлениях внутриминерализационной тектоники (Григорьев, 1961).
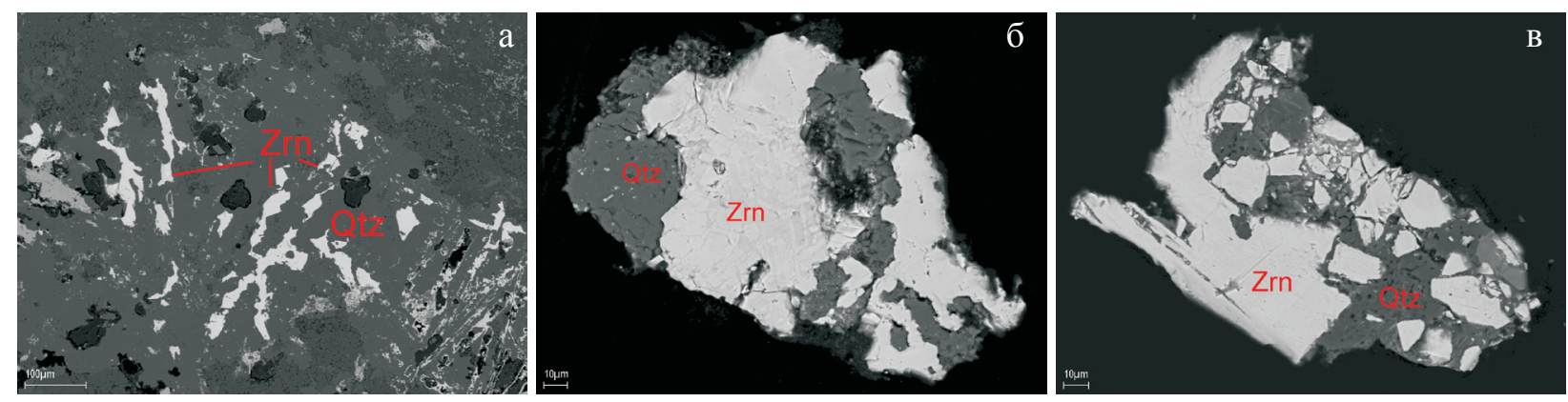

Рис. 4. Агрегаты циркона (Zrn) в кварце (Qtz). PЭМ, BSE-изображения.

Fig. 4. Zircon (Zrn) aggregates in quartz (Qtz). SEM, BSE images.

\section{Обсуждение предварительных результатов исследований}

Несомненно, что мы находимся лишь в самом начале изучения необычного геологического объекта, поэтому перечень минеральных видов далёк от ожидаемой полноты. Тем не менее, предварительные результаты исследований уже сейчас поставили ряд важнейших вопросов, связанных с генезисом этого геологического образования. Наличие хорошо образованных индивидов минералов, типичных для низко-среднетемпературных гидротерм, делает маловероятным образование каолинитовой зоны выветривания линейного типа только за счёт гипергенеза. Скорее всего, более правдоподобно пространственное совмещение некольких разновременных процессов, включая позднемагматическую тектонику и гидротермальную проработку, мезозойский и, возможно, современный гипергенез. При этом имеют право на жизнь и другие гипотезы, в том числе: эндогенный характер химического выветривания (метасоматоза) за счёт низко-среднетемпературных кислых гидротерм, образованных либо в ходе их естественной эволюции (постепенное повышение кислотности или гидролиз), либо за счёт подплавления вмещающих силикатных пород. Для получения ответов на эти и многие другие вопросы запланированы исследования несколькими рабочими группами, прежде всего, изотопно-геохимическое датирование циркона, петрология процессов и «тонкая» минералогия. 
Исследования объекта выполняются в рамках плановых НИР №№ 0226-2019-0051 и 0226-2019-0053.

\section{Литература}

1. Афанасьев А.П. Закономерности формирования кор выветривания и связанных с ними полезных ископаемых на Фанерозойском этапе развития Балтийского щита. / Автореферат диссертации на соискание учёной степени доктора геолого-минералогических наук. М.: ИГЕМ АН СССР. 1980 а. 59 с.

2. Афанасьев А.П. История формирования кор выветривания и гипергенных полезных ископаемых на Кольском полуострове в мезо-кайнозое // Геология и полезные ископаемые мезо-кайнозойских образований Кольского полуострова. Апатиты: КФ АН СССР. 1980 б. С. 5-36.

3. Григорьев Д.П. Онтогения минералов. 1961. Изд. Львовского ун-та. 284 с.

4. Дорфман М.Д. Геохимические особенности процессов выветривания в нефелиновых сиенитах Хибин. Геохимия. 1958. № 5. С. 424-434.

5. Дорфман М.Д. Минералогия пегматитов и зон выветривания в ийолит-уртитах горы Юкспор Хибинского массива. М.-Л. Изд-во АН СССР. 1962. С. 168.

6. Дудкин О.Б. Фанерозойские коры выветривания в щелочных массивах Кольского региона // Мурманский вестник. Т. 5. № 1. 2002. С. 3-8.

7. Жиров Д.В., Сим Л.А., Маринин А.В. Реконструкция палео стресс состояний в южной части Хибинского плутона (Восток Фенноскандинавского щита) // Труды Всероссийской научной конференции «Актуальные проблемы динамической геологии при исследовании платформенных областей». Москва, геологический факультет МГУ им. М.В. Ломоносова 24-26 мая 2016. М. Изд-во: Перо. 2016. С. 39-44.

8. Козырева Л.В. К вопросу о трещинных зонах выветривания на территории Хибинского массива // Сб. Коры выветривания и гипергенные полезные ископаемые восточной части Балтийского щита. Апатиты: КФАН АН СССР. 1983. С. 80-84.

9. Минералогия Хибинского массива (под ред. Чухрова Ф.В. Авторы: Коростылёва-Лабунцова Е.Е., Боруцкий Б.Е., Соколова М.Н., Шлюкова З.В., Дофман М.Д., Дудкин О.Б., Козырева Л.В., Икорский С.В.). Т. 1. М. Изд-во: Наука. 1978 а. 230 с.

10. Zircon. Reviews in Mineralogy \& Geochemistry. 2003. V. 53. J.M. Hanchar and P.W.O. Hoskin, eds. 